\title{
ANALISIS PENJAJARAN REKAM MEDIS STRAIGHT NUMERICAL FILING SYSTEM MENJADI TERMINAL DIGIT FILING SYSTEM DI RS FIRDAUS TAHUN 2021
}

\author{
Alfiah Nurripdah ${ }^{1 *}$, Dina Sonia ${ }^{2}$ \\ Rekam Medis dan Informasi Kesehatan, Politeknik Piksi Ganesha Bandung ${ }^{1,2}$ \\ piksi.alfiah.18303281@gmail.com ${ }^{1 *}$, nasoniaonya.ds@ gmail.com ${ }^{2}$
}

Received: 25-07-2021

Revised : $14-10-2021$

Accepted: 18-10-2021

\begin{abstract}
Abstrak
Latar Belakang: Ketersediaan berkas rekam medis secara cepat dan tepat pada saat yang dibutuhkan akan sangat membantu mutu pelayanan kesehatan yang diberikan kepada pasien, maka dari itu masalah penyimpanan berkas rekam medis merupakan hal yang penting untuk diperhatikan. Berdasarkan studi pendahuluan di Rumah Sakit Umum Firdaus, diketahui bahwa sistem penjajarannya sedang dalam tahap transisi perubahan dari sistem penjajaran straight numerical filing system menjadi terminal digit filing system.
\end{abstract}

Tujuan: Tujuan penelitian ini untuk membuat gambaran atau deskripsi tentang suatu keadaan secara objektif tentang perubahan sistem penjajaran straight numerical filing system menjadi terminal digit filing system dalam upaya meminimalisir kesalahan peletakan berkas rekam medis atau missed file.

Metode: Jenis penelitian yang digunakan deskriptif dengan metode observasional dan studi pustaka dengan pendekatan Cross Sectional.

Hasil: Hasil dari penelitian ini adalah prosedur perubahan diawali dengan mempersiapkan sarana dan prasarana, sumber daya manusia, dan pembongkaran berkas rekam medis di rak yang masih menggunakan sistem lama satu per satu serta menyusun ke dalam rak penyimpanan yang disusun secara terminal digit filing.

Kesimpulan: Berdasarkan hasil perubahan yang dilakukan ada beberapa kendala yang dihadapi, yaitu tempat dan rak filing yang kurang luas, dan sumber daya manusia yang tidak memadai serta saat melakukan penyimpanan dan pengambilan kembali berkas rekam medis masih ditemukan berkas rekam medis yang misfile. Dalam mengatasi terjadinya misfile dapat dilakukan dengan melakukan penyisiran berkas rekam medis secara periodik, mengaktifkan kembali penggunaan tracer, dan menerapkan kode warna pada berkas rekam medis pasien.

Kata kunci: rekam medis; sistem penjajaran; straight numerical filing; terminal digit filing. 


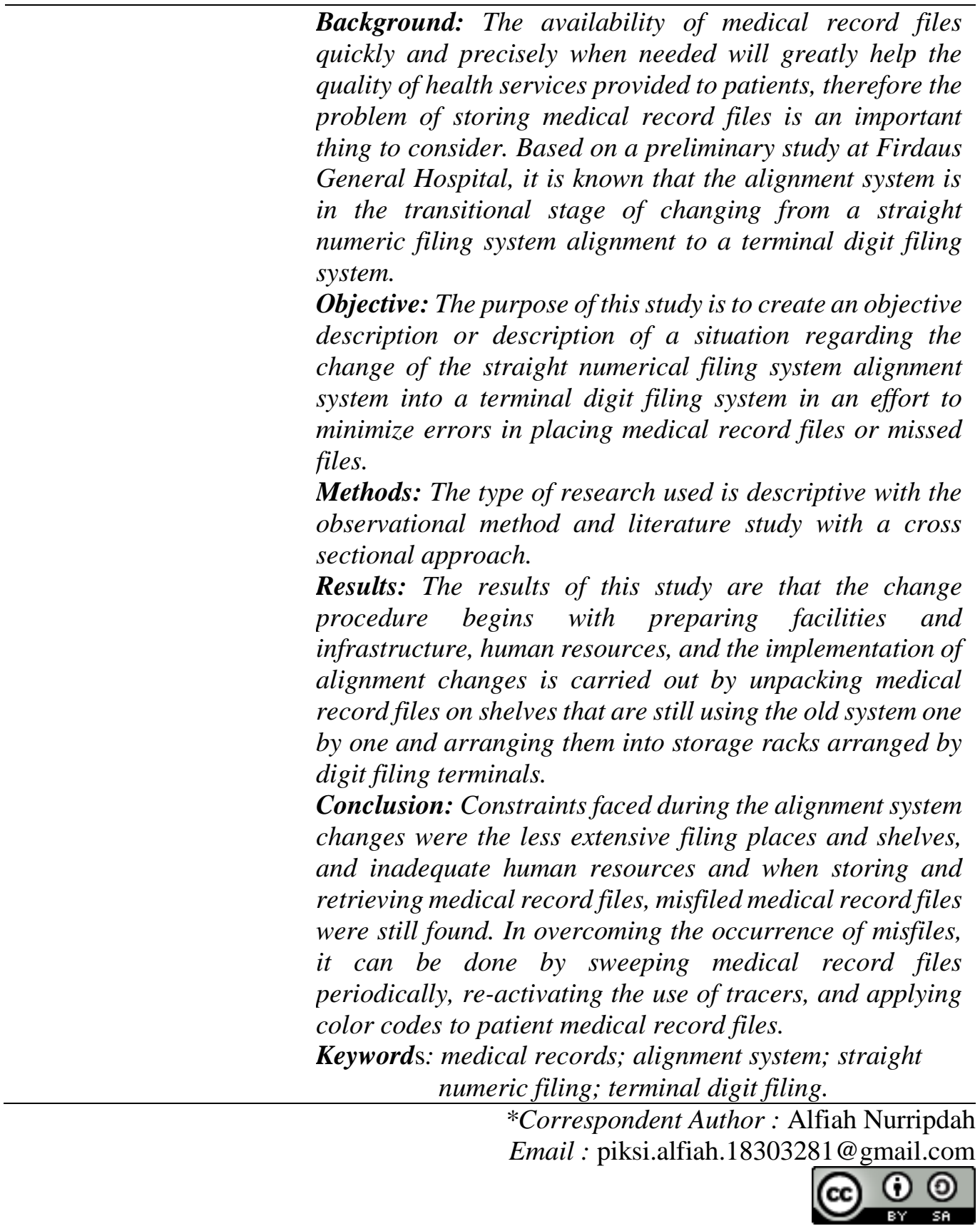

\section{PENDAHULUAN}

Setiap pelayanan yang diberikan kepada pasien di rumah sakit harus tercatat di dalam rekam medis Pengertian dari rekam medis itu sendiri menurut Permenkes No. 269/MENKES/PER/III/2008 pasal 1 Rekam Medis adalah berkas yang berisikan catatan dan dokumen tentang identitas pasien, pemeriksaan, pengobatan, tindakan dan pelayanan lain yang telah diberikan kepada pasien (Permenkes, 2008).

Rekam medis bersifat rahasia dan kewajiban Rumah Sakit untuk menjaga kerahasiaannya tertulis dalam UU No. 29 Tahun 2004 tentang Praktik Kedokteran, termasuk menjaga agar tidak hilang, dan tidak tidak dimanfaatkan oleh pihak yang tidak bertanggung jawab (Indonesia, 2004). Terselenggaranya manajemen informasi kesehatan 
dimulai dengan dibuatnya rekam medis secara baik dan benar oleh tenaga kesehatan pada sarana pelayanan kesehatan yang kemudian dikelola secara terencana (Hatta, 2013).

Menurut (Simanjuntak \& menkes.ris Sirait, 2018), penyimpanan berkas rekam medis sangatlah penting untuk melihat riwayat penyakit pasien dan kunjungan ulang pasien oleh sebab itu cara penyimpanan berkas rekam medis harus diatur dengan baik. Pengelolaan dokumen rekam medis yang ideal membutuhkan suatu sistem yang berguna sebagai bagian dari upaya untuk mewujudkan pengelolaan dokumen rekam medis yang lebih efektif dan efisien. Demikian pula penelitian yang telah dilakukan (Aso \& Sudalhar, 2019), tentang tinjauan pelaksanaan sistem penjajaran dokumen rekam medis pada bagian filing, menunjukkan sistem penjajaran terminal digit filing system, masih terdapat misfile dalam rak penyimpanan.

Salah satu bagian rumah sakit yang menunjang dalam pelayanan rekam medis pasien adalah bagian filing. Dimana salah satu tugas pokok bagian filing adalah menyimpan dokumen rekam medis yang sudah lengkap dengan metode penyimpanan angka akhir dan diurutkan sesuai nomor urutnya (Ernawati \& Lestari, 2014).

Pengelolaan sistem penjajaran yang tidak sesuai akan menyebabkan misfile karena dipengaruhi oleh faktor sumber daya manusia, serta sarana dan prasarana yang ada (Ernawati \& Lestari, 2014). Sistem Penjajaran yang paling tepat untuk menghindari kesalahan dalam penjajaran (misfile) yaitu menggunakan sistem penjajaran berdasarkan 2 angka kelompok terakhir (Terminal Digit Filing system) (Purwaningrum et al., 2019).

Berdasarkan survei pendahuluan pada tanggal 19 april 2021 di Rumah Sakit Firdaus diketahui bahwa sistem penyimpanannya secara sentralisasi dan sistem pengajarannya sedang dalam tahap transisi perubahan dari sistem penjajaran straight numerical filing system menjadi terminal digit filing system. Dikarenakan dalam pelaksanaan yang terdahulu masih ditemukan ketidaktepatan dalam penjajaran berkas rekam medis sehingga terjadi misfile saat rekam medis tersebut dibutuhkan kembali serta ruang penyimpanan dan rak yang terbatas mengakibatkan perlu dilakukannya perubahan tersebut dengan memfilter berkas rekam medis pasien dari 4-5 tahun terakhir berobat. Maka perlu dilakukan peralihan sistem penjajaran angka akhir yang lebih efektif sehingga dapat meminimalkan terjadinya potensi salah letak atau misfile tersebut dan tidak terjadi penumpukan akibat rak penyimpanan yang tidak memadai. Teori Aspirasi yang digunakan yaitu Sistem Penomoran Rekam Medis yang didapatkan saat mendaftar pertama kali di rumah sakit yang akan disimpan di rak filing sesuai urutan nomor rekam medisnya agar mempermudah pengambilan dan pengembalian dokumen rekam medis (Sari \& Sonia, 2021). Oleh karena itu, peneliti tertarik untuk melakukan penelitian ini.

\section{METODE PENELITIAN}

Metode penelitian yang digunakan pada penelitian ini adalah metode penelitian kualitatif dengan pendekatan deskriptif, yaitu suatu metode penelitian yang dilakukan dengan tujuan utama untuk membuat gambaran atau deskripsi tentang suatu keadaan secara objektif tentang perubahan sistem penjajaran straight numerical filing system menjadi terminal digit filing system dalam upaya meminimalisir kesalahan peletakan berkas rekam medis atau missed file (Anggito \& Setiawan, 2018). Pendekatan cross sectional yaitu suatu rancangan penelitian kesehatan dimana observasi dilakukan hanya sekali untuk memperoleh data yang lebih lengkap yang dilakukan dengan cepat dalam saat yang sama (Mumu et al., 2015). Dalam penelitian ini subyek yang digunakan adalah petugas filing, sedangkan objek penelitian adalah berkas rekam medis yang disimpan di ruang filing. Filing adalah kegiatan menyimpan dokumen rekam medis untuk mempermudah pengambilan yang disimpan di dalam rak penyimpanan (Suryanto et al., 2021).

Cara pengumpulan data yang digunakan adalah observasi yang dilaksanakan saat penulis melakukan praktek kerja lapangan pada bulan April s.d Juni 2021, Studi Pustaka, 
dan Sumber Data yang berasal dari kepala rekam medis dan petugas filing langsung serta berkas rekam medis pasien.

Instrumen penelitian yang digunakan yaitu Pedoman Wawancara berupa daftar pertanyaan yang sudah tersusun dan terencana dengan baik untuk mendapatkan informasi tentang kegiatan perubahan penjajaran berkas rekam medis yang dilakukan di ruang filing yang diperoleh dari kepala rekam medis dan petugas filing dan Pedoman Observasi yang ini berisi tentang jenis kegiatan yang akan diamati pada waktu penelitian adalah prosedur perubahan penjajaran berkas rekam medis yang dilakukan di ruang filing.

\section{HASIL DAN PEMBAHASAN}

\section{A. Hasil Penelitian}

1. Mengetahui pelaksanaan perubahan penjajaran di ruang filing

Rumah Sakit Firdaus dalam melakukan penyelenggaran rekam medis salah satunya adalah pelaksanaan penjajaran berkas rekam medis pasien rawat jalan, rawat inap, dan gawat darurat yang sedang dalam tahap transisi perubahan sistem penjajaran dari straight numerical filing system menjadi terminal digit filing system yaitu penjajaran dengan sistem angka akhir menggunakan 6 digit nomor yang terdiri dari 2 digit terakhir yang disebut dengan "Primary Digit", 2 digit yang ditengah yang disebut "Secondary Digit", 2 digit terdepan yang disebut "Tertiary Digit". yaitu:

Adapun cara yang dilakukan untuk melakukan transisi penjajaran tersebut

a. Semua berkas rekam medis dikeluarkan atau membongkar satu persatu setiap rak yang menggunakan sistem lama.

b. Menyiapkan tempat penyimpanan dengan menata ulang pembatasan sesuai dengan seksi-seksi kelompok angka di sistem angka akhir.

c. Rekam medis disortir kemudian dikelompokkan menurut kelompok 2 angka pertama, kelompok 2 angka kedua, dan kelompok 2 angka ketiga.

d. Memasukkan rekam medis sesuai dengan kelompok seksi.

Dalam melakukan perubahan penjajaran tersebut dilakukan oleh 8 orang yang bekerja disana yang sebenarnya 5 orang tersebut bagian pekerjaan nya bukan bagian filing.

2. Mengetahui sarana pengelolaan yang ada di ruang filing

a. Ruang penyimpanan dengan panjang 15 meter dan lebar 6 meter

b. Mempunyai rak filing tripleks tebal diantaranya 31 rak yang 1 muka rak terdiri dari 5 section yang terbagi menjadi 20 rak dalam penjajaran yang sudah berubah dan 11 rak yang masih dalam penjajaran yang lama

c. Tidak terdapat kode warna untuk pembedaan berkas rekam medis satu dengan lainnya

d. Buku ekspedisi untuk serah terima berkas rekam medis

e. Tidak menggunakan tracer

f. Ruangan menggunakan $\mathrm{AC}$

3. Mengetahui kejadian misfile DRM yang teradi di ruang filing

Berdasarkan observasi yang dilakukan pada tanggal 26 April -8 Mei 2021, dalam hal kejadian misfile yang terjadi di RS Firdaus yaitu:

Tabel 1. Kejadian misfile DRM yang terjadi di filing

\begin{tabular}{lll}
\hline No Tanggal observasi & BRM yang misfile \\
\hline
\end{tabular}

Analisis Penjajaran Rekam Medis Straight Numerical Filing System Menjadi Terminal

Digit Filing System di RS Firdaus Tahun 2021 


\begin{tabular}{clccc}
\hline 2 & $\begin{array}{c}\text { Jumlah BRM } \\
\text { yang dilayani } \\
\text { di } \text { filing }\end{array}$ & jumlah & \% \\
\hline 1. & Senin, 26 April 2021 & 320 BRM & 8 & 2,5 \\
\hline 2. & Selasa, 27 April 2021 & 225 BRM & 2 & 0,9 \\
\hline 3. & Sabtu, 1 Mei 2021 & 278 BRM & 4 & 1,4 \\
\hline 4. & Rabu, 5 Mei 2021 & 234 BRM & 2 & 0,8 \\
\hline 5. & Jumat, 7 Mei 2021 & 265 BRM & 6 & 2,3 \\
\hline 6. & Sabtu. 8 Mei 2021 & 310 BRM & 1 & 0,3 \\
\hline & Jumlah & 1632 BRM & 23 & 1,4 \\
\hline
\end{tabular}

Berdasarkan tabel 1, kejadian misfile yang terendah terjadi pada tanggal 8 Mei 2021 sebesar 0,3\% dan yang tertinggi terjadi pada tanggal 26 April 2021 sebesar $2.5 \%$.

Di RS Firdaus dalam mengatasi kejadian misfile dengan cara menelusuri ke setiap rak dikhawatirkan salah penyimpanan oleh petugas dan bisa juga dengan membuat berkas rekam medis yang baru. Namun sebelum membuat berkas rekam medis yang baru petugas harus memberitahukan ke bagian pelayanan kesehatan di poliklinik bahwa berkas rekam medis pasien tersebut tidak dapat ditemukan. Pembuatan berkas rekam medis baru itu dilakukan untuk mempercepat proses pelayanan kepada pasien, namun risiko yang terjadi adalah dokter yang melayani pasien tidak dapat mengetahui riwayat kesehatan pasien atau tindakan sebelumnya yang di derita oleh pasien tersebut.

\section{B. Pembahasan}

1. Pelaksanaan perubahan penjajaran di ruang filing

Sistem penjajaran merupakan sistem yang digunakan untuk melakukan penyimpanan rekam medis di dalam rak dengan cara dijajar. Berdasarkan cara penjajaran menurut nomor rekam medis, maka sistem penjajaran dapat dikelompokkan menjadi sistem nomor langsung (Straight Numerical Filing), sistem angka tengah (Middle Numerical Filing), dan sistem angka akhir (Terminal digit filing) (Widjaja \& Dewi, 2017).

Menurut penelitian (Yani, 2017) yang menyatakan bahwa Sistem Penjajaran Terminal digit filing (TDF) itu lebih baik dari pada sistem penjajaran Straight Numerical Filing (SNF) untuk menghindari terjadinya misfile. Hal ini dikarenakan sistem Terminal digit filing (TDF) memudahkan dalam pengambilan dan penyimpanan kembali dokumen rekam medis dan menjaga kerahasiaan berkas rekam medis pasien (Wati \& Pujihastuti, 2011).

Penjajaran rekam medis dengan sistem Terminal digit filing (TDF) dilakukan dengan cara petugas melihat dua digit angka secara bertahap, dimulai dua digit angka primer (terakhir) untuk menemukan letak rak penyimpanan selanjutnya melihat angka sekunder (kedua) untuk menemukan sub rak dan diakhiri dengan angka tersier (ketiga) untuk menyimpan rekam medis. Cara penjajaran Terminal digit filing (TDF) tersebut meminimalkan kekeliruan penyimpanan (Suhartinah et al., 2019). Sedangkan menurut (Tunnisa \& Erviana, 2020) disampaikan bahwa Terminal digit filing (TDF) beresiko terjadinya kesalahan pengambilan rekam medis pada saat proses pencarian rekam medis lama apabila fasilitas pelayanan kesehatan tidak tertib dalam menggunakan tracer. Contoh penjajaran dokumen rekam medis secara Terminal digit filing (TDF) yaitu nomor 032578 ditulis dengan cara:03-25-78 tersier sekunder primer.

Adapun kelebihan dan kekurangan sistem Terminal digit filing (TDF) menurut (Depkes RI, 2014) yaitu: 
a. Kelebihan sistem penjajran Terminal digit filing adalah:

1) Penambahan jumlah dokumen rekam medis selalu tersebar secara merata ke 100 kelompok (section) di dalam rak penimpanan. Petugas-petugas penyimpanan tidak akan terpaksa berdesakan disatu tempat atau section, dimana rekam medis harus disimpan di rak.

2) Petugas-petugas dapat diserahi tanggung jawab untuk sejumlah section tertentu misalnya ada 4 petugas masing-masing diserahi: section 00-24, section 25-49, section 50-74, section 75-99.

3) Pekerjaan akan terbagi rata mengingat setiap petugas rata-rata mengerjakan jumlah rekam medis yang hampir sama setiap harinya untuk setiap section sehingga mudah mengingat letak dokumen rekam medis.

4) Rekam medis yang tidak aktif dapat diambil dari rak penyimpanan dari setiap section, pada saat ditambahnya rekam medis baru di section tersebut.

5) Jumlah rekam medis untuk setiap section terkontrol dan bisa dihindarkan timbulnya rak-rak kosong.

6) Dengan terkontrolnya rekam medis, membantu memudahkan perencanaan peralatan penyimpanan (jumlah rak).

7) Kekeliruan menyimpan (misfile) dapat dicegah, karena petugas penyimpanan hanya memperhatikan 2 angka saja dalam memasukkan rekam medis kedalam rak, sehingga jarang terjadi kekeliruan membaca angka.

b. Kekurangan sistem penjajaran Terminal digit filing (TDF)

1) Latihan dan bimbingan bagi petugas penyimpanan dalam hal sistem angka akhir, mungkin lebih lama dibandingkan latihan menggunakan sistem nomor langsung tetapi umumnya petugas dapat dilatih dalam waktu yang tidak lama.

2) Membutuhkan biaya awal lebih besar karena harus menyiapkan rak penyimpanan terlebih dahulu.

Untuk melakukan transisi perubahan penjajaran tersebut semua berkas rekam medis dikeluarkan atau membongkar satu per satu setiap rak yang menggunakan sistem lama, menata ulang pembatasan tempat penyimpanan sesuai dengan seksi-seksi kelompok lalu berkas rekam medis disortir dan dikelompokkan menurut kelompok 2 angka pertama, kelompok 2 angka kedua, dan kelompok 2 angka ketiga setelah semua selesai berkas rekam medis dimasukkan kembali ke rak sesuai dengan kelompok seksi. Dalam melakukan perubahan penjajaran tersebut dilakukan oleh 8 orang yang bekerja disana yang sebenarnya 5 orang tersebut bagian pekerjaan nya bukan bagian filing.

2. Sarana pengelolaan yang ada di ruang filing

Dengan luas ruang filing yang tidak terlalu besar mengakibatkan ketidaknyamanan petugas saat mengambil dan mengembalikan berkas rekam medis. Untuk rak filing masih menggunakan tripleks tebal yang sewaktu-waktu bisa mengakibatkan rak tersebut tidak mampu menahan atau menampung dengan semakin bertambah nya berkas rekam medis pasien yang baru. Penggunaan AC di ruang filing berfungsi untuk menjaga suhu dan kelembaban dalam ruangan sehingga tidak merusak kualitas berkas rekam medis pasien.

Dalam penggunaan buku ekspedisi harus dijalankan sebagaiman semestinya, jika penggunaannya kurang maksimal menjadi salah satu factor tingginya misfile, karena terkadang petugas filing bagian distribusi tidak mencatat berkas rekam medis yang di anter menuju poliklinik yang dituju. Buku ekspedisi berfungsi sebagai bukti serah terima berkas rekam medis, untuk mengetahui unit mana yang meminjam berkas rekam medis dan untuk mengetahui kapan berkas rekam medis itu dikembalikan. Jika buku ekspedisi tidak digunakan dengan maksimal, maka akan sulit melacak berkas rekam medis saat terjadinya misfile. 
Menurut (Tunnisa \& Erviana, 2020) disampaikan bahwa Terminal digit filing System beresiko terjadinya kesalahan pengambilan rekam medis pada saat proses pencarian rekam medis lama apabila fasilitas pelayanan kesehatan tidak tertib dalam menggunakan tracer. Tidak adanya tracer dalam rak filing akan menyebabkan kesulitan untuk mengembalikan berkas rekam medis ke tempat semula, karena secara teori tracer adalah suatu alat yang penting untuk melacak keberadaan berkas rekam medis. Hal ini belum sesuai dengan (RI, 2006) bahwa tracer berguna untuk mengawasi pengunaan dokumen rekam medis dan sebagai berkas rekam medis yang dipinjam dan pengambilan berkas rekam medis harus menggunakan tracer atau kartu peminjam berkas rekam medis. Dalam penggunaannya tracer diletakan sebagai pengganti berkas rekam medis yang di ambil (dikeluarkan) dari rak penyimpanan. Oleh karena itu tracer berfungsi untuk mempermudah dalam pengembalian berkas rekam medis pada rak yang sesuai sehingga mengurangi terjadinya misfile.

Namun dalam pelaksanaan sistem penjajaran di RS Firdaus masih ditemukan salah simpen (misfile) pada saat petugas akan mengambil berkas rekam medis. Hal yang juga dapat memicu terjadinya misfile, karena pada berkas rekam medis masih belum menggunakan kode warna. Adapun strategi untuk mencegah misfile dengan pemberian kode warna menurut (Ri, 2006) bahwa kode warna pada sampul rekam medis memberikan warna tertentu untuk mencegah keliru simpan dan memudahkan mencari berkas rekam medis yang salah (misfile). Garis-garis warna dengan posisi yang berbeda-beda untuk setiap seksi penyimpanan rekam medis. Terputusnya kombinasi warna dalam satu seksi penyimpanan menunjukkan adanya kekeliruan penyimpanan berkas rekam medis.

3. Kejadian misfile berkas rekam medis yang terjadi di ruang filing

Secara teori, kejadian misfile yang terjadi seharusnya $0 \%$. Sedangkan fakta yang ada dilapangan, persentase kejadian misfile mencapai 1,4\%. Kejadian misfile yang terendah terjadi pada tanggal 8 Mei 2021 sebesar 0,3\% dan yang tertinggi terjadi pada tanggal 26 April 2021 sebesar $2.5 \%$. Bila sering terjadi misfile akan menghilangkan informasi medis pasien sehingga akan menimbulkan ketidaktahuan dokter/perawat apabila pasien mempunyai riwayat alergi yang dideritanya dan hal tersebut berdampak pada pengobatan pasien tersebut.

Dalam mengatasi kejadian misfile tersebut dengan cara menelusuri ke setiap rak dikhawatirkan salah penyimpanan oleh petugas dan bisa juga dengan membuat berkas rekam medis yang baru. Namun sebelum membuat berkas rekam medis yang baru petugas harus memberitahukan ke bagian pelayanan kesehatan di poliklinik bahwa berkas rekam medis pasien tersebut tidak dapat ditemukan. Pembuatan berkas rekam medis baru itu dilakukan untuk mempercepat proses pelayanan kepada pasien, namun risiko yang terjadi adalah dokter yang melayani pasien tidak dapat mengetahui riwayat kesehatan pasien atau tindakan sebelumnya yang di derita oleh pasien tersebut.

\section{KESIMPULAN}

Berdasarkan hasil perubahan penjajaran rekam medis straight numerical filing system menjadi terminal digit filing system di Rumah Sakit Firdaus maka dapat disimpulkan bahwa yang dilakukan ada beberapa kendala yang dihadapi, yaitu tempat dan rak filing yang kurang luas, dan sumber daya manusia yang tidak memadai serta saat melakukan penyimpanan dan pengambilan kembali berkas rekam medis masih ditemukan berkas rekam medis yang misfile. Kejadian misfile mencapai 1,4\%. Kejadian misfile terendah terjadi pada 
tanggal 8 Mei 2021 sebesar 0,3\% dan yang tertinggi terjadi pada tanggal 26 April 2021 sebesar $2.5 \%$.

Dalam mengatasi terjadinya misfile dapat dilakukan dengan cara menelusuri ke setiap rak dikhawatirkan salah penyimpanan oleh petugas secara periodik, bisa juga dengan membuat berkas rekam medis yang baru, menggunakan tracer dan memaksimalkan penggunaan buku ekspedisi agar mempermudah dalam pencarian berkas rekam medis dan penyimpanan berkas rekam medis pasien, dan menerapkan kode warna pada berkas rekam medis pasien untuk mencegah keliru simpan dan memudahkan mencari berkas rekam medis yang salah (misfile).

\section{BIBLIOGRAFI}

Anggito, A., \& Setiawan, J. (2018). Metodologi penelitian kualitatif. CV Jejak (Jejak Publisher).

Aso, K., \& Sudalhar, T. (2019). Tinjauan Pelaksanaan Sistem Penjajaran Dokumen Rekam meids Pada Bagian Filing UPTD Puskesmas Bojonegoro. Jurnal Hpospita Science, 3(1), 103-108.

Depkes RI. (2014). Peraturan Menteri Kesehatan Republik Indonesia Nomor 9 Tahun 2014 Tentang Klinik. Menteri Kesehatan Republik Indonesia Peraturan Menteri Kesehatan Republik Indonesia, Nomor 65(879), 2004-2006.

Ernawati, S., \& Lestari, T. (2014). Tinjauan Pelaksanaan Sistem Penjajaran Dokumen Rekam Medis di Bagian Filing RSUD Kabupaten Sukoharjo Tahun 2013. Rekam Medis, 7(1).

Hatta, G. R. (2013). Pedoman Manajemen Informasi Kesehatan Disarana Pelayanan Kesehatan (Revisi 2). Jakarta: Universitas Indonesia.

Indonesia, R. (2004). Undang-Undang Nomor 29 Tahun 2004 tentang Praktik Kedokteran. Jakarta: Republik Indonesia.

Mumu, L. J., Kandou, G. D., \& Doda, D. V. (2015). Analisis Faktor-Faktor Yang Berhubungan Dengan Kepuasan Pasien di Poliklinik Penyakit Dalam RSUP Prof . Dr . R . D . Kandou Manado Clinic of Internal Medicine Department of RSUP Prof . Dr . R . D . Kandou. Jurnal Unsrat, 1.

Permenkes, R. I. (2008). No 269/Menkes/Per/III/2008 tentang Rekam Medis. Jakarta: Menteri Kesehatan Reupublik Indonesia.

Purwaningrum, S. N., Khasanah, L., \& Karmanto, B. (2019). Rancangan Manajemen Filing dan Desain Formulir Pelayanan Kesehatan Umum di Puskesmas Sunyaragi Kota Cirebon. Edukasi Masyarakat Sehat Sejahtera (EMaSS): Jurnal Pengabdian Kepada Masyarakat, 1(1), 86-91. https://doi.org/10.37160/emass.v1i1.194

Ri, D. (2006). Pedoman Penyelenggaraan dan Prosedur Rekam Medis Rumah Sakit di Indonesia. Jakarta: Depkes RI.

RI, D. (2006). Pedoman Penyelenggaraan \& Prosedur Rekam Medis Rumah Sakit di Indonesia Revisi II. REVISI II.

Sari, L. N., \& Sonia, D. (2021). Perhitungan Kebutuhan Rak Penyimpanan Dokumen Rekam Medis di Ruang Filing RSIA Humana Prima Bandung Tahun 2021. Cerdika: Jurnal Ilmiah Indonesia, 1(8), 1004-1012. https://doi.org/10.36418/cerdika.v1i8.145

Simanjuntak, E., \& menkes.ris Sirait, L. W. O. (2018). Faktor-faktor penyebab terjadinya missfile di bagian penyimpanan berkas rekam medis rumah sakit mitra medika medan tahun 2017. Jurnal Ilmiah Perekam Dan Informasi Kesehatan Imelda (JIPIKI), 3(1), 370-379.

Suhartinah, S., Anwar, A. C., Anggryani, F., \& Juwita, R. (2019). Analisa mutu sistem penyimpanan dokumen rekam medis di rumah sakit umum pindad turen. SMIKNAS, 116-124.

Analisis Penjajaran Rekam Medis Straight Numerical Filing System Menjadi Terminal Digit Filing System di RS Firdaus Tahun 2021 
Suryanto, H., Munawwarah, A., \& Fitriyana, B. A. (2021). Perhitungan Kebutuhan Rak Penyimpanan Dokumen Rekam Medis Dan Luas Ruang Filing Di Rumah Sakit Tahun 2020-2024. Jurnal Rekam Medis Dan Informasi Kesehatan, 4(1), 8-17.

Tunnisa, U., \& Erviana, N. (2020). Manajemen Resiko Redesign Sistem Penjajaran Rekam Medis dengan Metode Failure Mode and Effect Analysis (FMEA). Indonesian of Health Information Management Journal (INOHIM), 8(1), 8-20. https://doi.org/10.47007/inohim.v8i1.204

Wati, O. M., \& Pujihastuti, A. (2011). Tinjauan Pelaksanaan Penyimpanan dan Penjajaran Dokumen Rekam Medis di Ruang Filing RSUD dr. Moewardi. Rekam Medis, 5(2).

Widjaja, L., \& Dewi, D. R. (2017). Manajemen Informasi Kesehatan II: Sistem dan Sub Sistem Pelayanan RM. Bahan Ajar RMIK. PPSDM Kemenkes.

Yani, S. J. A. (2017). Tinjauan Waktu Penyediaan dan Faktor Penyebab Keterlambatan Pendistribusian Rekam Medis Rawat Jalan di Rumah Sakit Condong Catur Yogyakarta Tahun 2017.

(C) 2021 by the authors. Submitted for possible open access publication under the (c) (i) (2) terms and conditions of the Creative Commons Attribution (CC BY SA) license (https://creativecommons.org/licenses/by-sa/4.0/). 